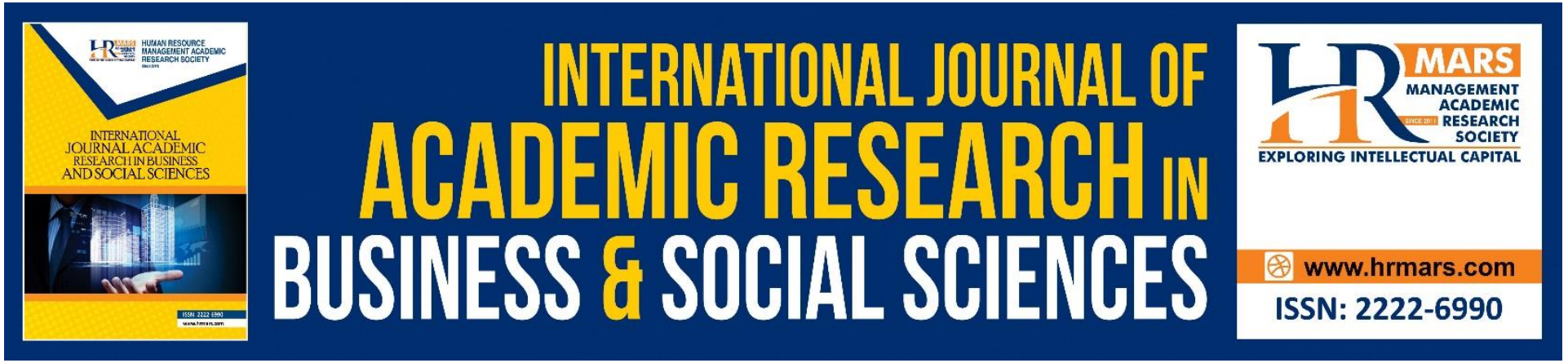

\title{
Discussion of the AR Design Principles for Mobile Augmented Reality Games
}

Fasehah Abdullah, Azhar Abd. Jamil, Mohamed Razeef Abdul Razak

To Link this Article: http://dx.doi.org/10.6007/IJARBSS/v11-i8/10738

DOI:10.6007/IJARBSS/v11-i8/10738

Received: 20 June 2021, Revised: 23 July 2021, Accepted: 01 August 2021

Published Online: 14 August 2021

In-Text Citation: (Abdullah et al., 2021)

To Cite this Article: Abdullah, F., Jamil, A. A., \& Razak, M. R. A. (2021). Discussion of the AR Design Principles for Mobile Augmented Reality Games. International Journal of Academic Research in Business and Social Sciences, 11(8), 375-380.

Copyright: ( 2021 The Author(s)

Published by Human Resource Management Academic Research Society (www.hrmars.com)

This article is published under the Creative Commons Attribution (CC BY 4.0) license. Anyone may reproduce, distribute, translate and create derivative works of this article (for both commercial and non-commercial purposes), subject to full attribution to the original publication and authors. The full terms of this license may be seen at: http://creativecommons.org/licences/by/4.0/legalcode

Vol. 11, No. 8, 2021, Pg. 375 - 380

Full Terms \& Conditions of access and use can be found at http://hrmars.com/index.php/pages/detail/publication-ethics 


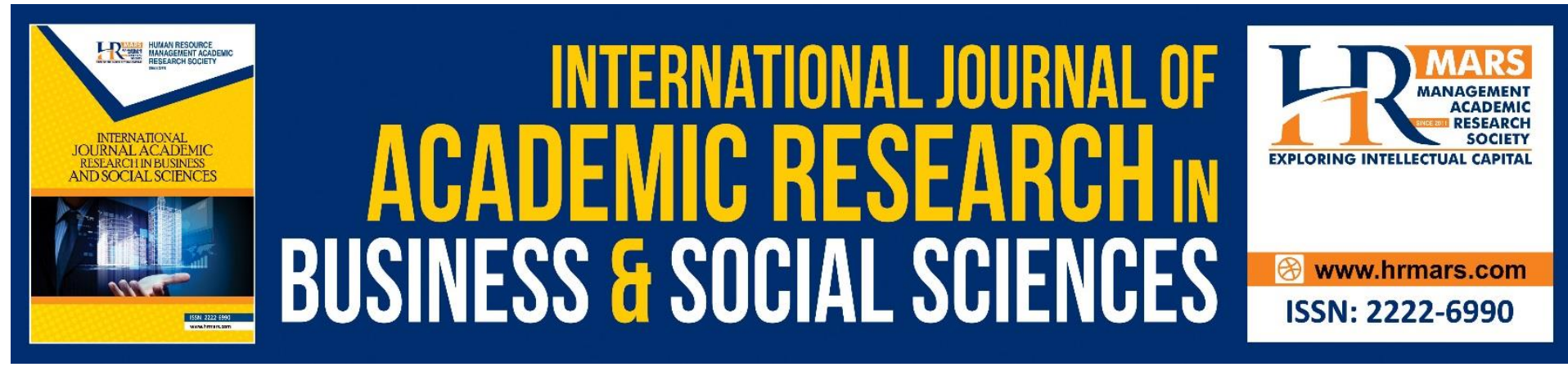

\title{
Discussion of the AR Design Principles for Mobile Augmented Reality Games
}

\author{
Fasehah Abdullah¹, Azhar Abd. Jamil², Mohamed Razeef Abdul \\ Razak $^{3}$ \\ ${ }^{1}$ Faculty of Arts and Design, Southern University College, ${ }^{2}$ Faculty of Arts and Design, UiTM \\ Shah Alam, ${ }^{3}$ Faculty of Arts and Design, UiTM Shah Alam, Malaysia
}

\begin{abstract}
Mobile Augmented Reality (MAR) is a unique creation in the game playing field between digital and real physical environment surroundings the players. Designing mobile augmented reality games is a challenging mission and observation is needed every perspective in creating an enjoyable and exciting player experience. This paper will discuss existing research to review the design principles of mobile augmented reality for games. The discussion on the current AR design principles in MAR would assist in identifying potential elements of $A R$ design principles as design guidelines for AR for designers and educators respectively.

Keywords: Design Principles and Mobile Augmented Reality Games.
\end{abstract}

\section{Introduction}

New developments in augmented and virtual reality investments are rapidly sustaining growth, the survey of a new finding by global law firm Perkins Coie LLP shows respondents have chosen gaming as the segment they predict will attract the utmost investment for the next coming year, (Coie, 2018). The survey of professional respondents shows that most of them are currently developing video games for AR/VR (39\%) in 2018 and that is the highest percentage among eight different types of content such as video games, movies and entertainment, social media, advertisement, music, news and visual stories, livestream, and others. However, there was insufficient research on the guidelines of the MAR game in the research segment and this statement was supported by Liang (2016), she highlighted the lack of research about the theoretical framework or the principles of AR design. The principles of design for augmented reality are mostly overlooked as there is little information in this particular part and very limited design guidelines have been established. In order to create a better version of MAR games design, the fundamental principles of AR design are useful and as guidelines for AR designers and educators to create a quality MAR games design, (Dunser et al., 2018),

\section{Mobile Augmented Reality Games}

According to Dirin and Laine (2018), clarified simulated content in MAR games can be shown in a number of forms such as animations, three-dimensional modeling, and videos. For example, the Snapchat instant messaging application and the Pokémon Go game are fast 
becoming new trendy $A R$ features in smartphones and this trend in new technology has improved players' and developers' views and reactions to these features.

According to Statista (2017), clearly stated young generation spends more time with their mobile devices from 107 minutes in 2012 to 223 minutes in 2017. Most of the time they spend on mobile games, which is why they make the greatest contribution to the rapid growth rate of mobile devices used. Action and arcade games becoming current trendy mobile genres have been downloaded more than 60 million times in 2016.

According to Statista (2018), determined the market size of Global Mobile Augmented Reality growing faster over five years. Starting from 2013, users of 60 million mobile augmented reality had increased and continued to grow over 200 million users by 2018 .

\section{Design Principles of Mobile Augmented Reality Games}

In the learning study, AR games can increase self-motivation and a well-designed AR game can also have a positive influence to the game play process, (Ferrer et al., 2013). The previous researcher discovered that the AR interaction technique offers new gaming experience but it requires simple $A R$ design to coax the player from paying too much attention to technology instead of playing games, (Permadi \& Rafi, 2016).

Fortunately, the current augmented reality research has established minimal guiding principles, design systems and evaluation approaches, (Huang, Alem \& Livingston, 2012). Another discussion about design challenges for AR designers was made regarding how knowledge could be structured and linked in a rapidly evolving real world in a way that prevents users from intellectually overloading arising from the significant amount of data available? (Kourouthanassis et al., 2015). From this citation, there may be good reason to focus specifically on the identification of appropriate AR design principles.

From published literature, MAR applications show great potential in user application interaction, but less of design principles and guidance for researchers and experts to design using an acceptable method, (Kourouthanassis et al., 2015).

This paper studied the design principles of mobile augmented reality applications and games. It reviewed the existing MAR applications and games available in the digital market based on discussions from previous researchers. Three researchers have come up with instructive design principles elements herein.

Beginning with Höllerer (2004), the researcher covered five elements of augmented reality such as consistency, control, display space, scene dynamics, and need for embedded semantic information. The researcher highlighted Mobile AR GUIs need to face with complex task compared to traditional 2D graphic design and need to face with an unlimited display space surrounding the user. The situation of augmented space depends on the user's position. Next, Kourouthanassis et al (2015), also focused on the five elements that were suitable with AR such as using the context for providing content, delivering relevance to the task content, informing users about content privacy, providing feedback about the infrastructure's behaviour, and supporting procedural and semantic memory. However, it contradicts with Liang (2016), who covered six elements of augmented reality such as user, interaction, virtual content, actual content, device, physical or real world and tracking. In this research, visual elements such as animation, video, sound and others inside virtual contents are mentioned, as well as virtual contents such as 3D model objects, 2D design or images, and text. Each year, we would see the researchers make a strong enhancement in upgrading quality in augmented reality with appropriate design principles. 


\section{Discussions of Design Principles and Approach}

This paper empirically reviewed the discussion of Mobile Augmented Reality's usage and approach design principles of from past literature review. Höllerer (2004), specified five different types design principles to guide the design of AR applications. First, consistency when using computer users automatically can adapt the rationale of a new User Interface as long it has desktop setting. However, it different with mobile augmented reality system, and caution must take when designing interfaces to ensure the real and virtual worlds are compatible with one another. The User Interface technique must either loosen the nonocclusion criteria or guarantee non-occlusion in the face of potential contingencies. Secondly, control is different with desktop User Interface, in which the only way for the user to connect with the simulated environment is via a series of clearly defined techniques. For example, a User Interface technique may focus on a specific object being visible to the user and not obscured by other details. Thirdly, display space might compete with a variety of difficult challenges opposed to conventional 2D interfaces. The recognition of that area of augmented space is determined by the user's personal setting, location, and head-orientation. Fourthly, scene dynamics, the scene in a mobile and head-tracked UI can be even more dynamic than in a static version. Since mobile augmented reality system device potentially move objects in the physical world that could interact with the User Interface shown on the head-worn monitor. Because of these random dynamics, the UI screen configuration must be adjustable, and the design of visual elements need to be modified. Finally, there is a need for embedded semantic information in mobile augmented reality system to exist in order to identify $\mathrm{UI}$ behavior patterns, and explicit semantic relationships between virtual and real objects must be created. Indeed, since certain simulated objects are designed to analyses the physical environment, virtual objects must load or access data about the real objects. The researcher mentioned most of the research community generally agrees on the majority of the elements of AR systems, supported by the sharing of ideas and discussions via international conferences but it still had minor variations in belief and perception.

Kourouthanassis et al (2015), found that most of the AR-related studies focused on software and hardware issues. The researcher stated five different types of design principles to guide the design of AR applications. First, use the context to provide content, and the result shows strong functionality and system efficiency in terms of improving user friendly interaction. Second, deliver relevance to the task content, and the finding shows enhanced user experience (UX) in terms of functionality and effectiveness in discovery information that relevant to user usage, and the ability to create innovative user-system experiences. Third, inform about content privacy, and the outcome shows the user concerns about the use of their personal data. Fourth, provide feedback about the infrastructure's behavior, and it can reduce of user frustration and increase user satisfaction through feedback messages. Fifth, support procedural and semantic memory, and the result shows users preferred clear and reasonable function in AR system design. The researcher highlighted each design principles and interpreted these principles to overcome augmented reality design issues.

Liang (2016) highlighted that, virtual content is the important element in the augmented reality architecture. The conceptual model element for virtual contents such as 3D animations and model objects, 2D design or images, website, text, audio or sound information, and vibration. The researcher used six elements of augmented reality architecture such as user, interaction, virtual content, actual content, device, physical or real world and tracking. This is to set the limits of augmented reality and to specify the option available in the function of $A R$ for specific activities. This approach from the research of 15 Augmented Reality journals for 
elderly adults shows the scope study in terms of entertainment, on-site place, training, and transportation.

\section{Conclusion}

This paper discussed instructive design principles of mobile augmented reality applications and games. There are five to six elements mentioned from three different researchers and the finding shows that all three researchers highlighted semantic in information and memory, and the usage of providing task content (virtual and actual content in mobile augmented reality).

The significance of this discussion is to identify the basic potential elements in design principles of mobile augmented reality. These findings will assist junior AR designers or beginners and educators in implementing fundamental elements in design principles during the early stages of the design process while constructing MAR game designs.

\section{Corresponding Author}

Fasehah Binti Abdullah

Faculty of Arts and Design, Southern University College and UiTM Shah Alam.

Email: fasehah@sc.edu.my

\section{References}

\section{Journal article}

Dirin, A., \& Laine, T. H. (2018). User experience in mobile augmented reality: emotions, challenges, opportunities and best practices. Computers, 7(2), 33.

Dünser, A., Grasset, R., Seichter, H., \& Billinghurst, M. (2018). Applying $\mathrm{HCl}$ principles to AR systems design. HIT Lab NZ.

Ferrer, V., Perdomo, A., Rashed-Ali, H., Fies, C., \& Quarles, J. (2013). How does usability impact motivation in augmented reality serious games for education? In 2013 5th International Conference on Games and virtual worlds for serious applications (VSGAMES) (pp. 1-8). IEEE.

Höllerer, T. (2004). User interfaces for mobile augmented reality systems (Doctoral dissertation, Columbia University).

Huang, W., Alem, L., \& Livingston, M. A. (Eds.). (2012). Human factors in augmented reality environments. Springer Science \& Business Media.

Kourouthanassis, P. E., Boletsis, C., \& Lekakos, G. (2015). Demystifying the design of mobile augmented reality applications. Multimedia Tools and Applications, 74(3), 1045-1066.

Kourouthanassis, P., Boletsis, C., Bardaki, C., \& Chasanidou, D. (2015). Tourists responses to mobile augmented reality travel guides: The role of emotions on adoption behavior. Pervasive and Mobile Computing, 18, 71-87.

Liang, S. (2016). Design principles of augmented reality focusing on the ageing population. In Proceedings of the 30th International BCS Human Computer Interaction Conference 30 (pp. 1-7).

Coie, P. (2018). Augmented and virtual reality survey report. Perkins Coie, 1-20.

Permadi, D., \& Rafi, A. (2016). Empirical analysis of mobile augmented reality games for engaging users' experience. In Intelligent and evolutionary systems (pp. 343-355). Springer, Cham. 
INTERNATIONAL JOURNAL OF ACADEMIC RESEARCH IN BUSINESS AND SOCIAL SCIENCES Vol. 11, No. 8, 2021, E-ISSN: 2222-6990 @ 2021 HRMARS

\section{Online Newspaper Articles}

Statista - The Statistic. (2018). Augmented Reality - Statistics and Facts.

Retrieved from https://www.statista.com/topics/3286/augmented-reality-ar/ Statista - The Statistic. (2017). Mobile Gaming Industry - Statistics and Facts.

Retrieved from https://www.statista.com/topics/1906/mobile-gaming/ 